\title{
Neuronal Damage and Neuroinflammation, a Bridge Between Bacterial Meningitis and Neurodegenerative Diseases
}

\author{
Kristine Farmen ${ }^{\dagger}$, Miguel Tofiño-Vian ${ }^{\dagger}$ and Federico lovino* \\ Department of Neuroscience, Karolinska Institutet Biomedicum, Stockholm, Sweden
}

OPEN ACCESS

Edited by:

Noriko Shinjyo,

Osaka University, Japan

Reviewed by:

Paulina Carriba,

Cardiff University, United Kingdom

Mathieu Coureuil,

Institut National de la Santé et de la

Recherche Médicale (INSERM),

France

*Correspondence:

Federico lovino

federico.iovino@ki.se

tThese authors have contributed equally to this work and share first

authorship

Specialty section:

This article was submitted to Cellular Neuropathology,

a section of the journal

Frontiers in Cellular Neuroscience

Received: 15 March 2021 Accepted: 03 May 2021

Published: 03 June 2021

Citation:

Farmen K, Tofiño-Vian M and lovino F (2021) Neuronal Damage and

Neuroinflammation, a Bridge Between Bacterial Meningitis and Neurodegenerative Diseases. Front. Cell. Neurosci. 15:680858. doi: 10.3389/fncel.2021.680858
Bacterial meningitis is an inflammation of the meninges which covers and protects the brain and the spinal cord. Such inflammation is mostly caused by bloodborne bacteria that cross the blood-brain barrier (BBB) and finally invade the brain parenchyma. Pathogens such as Streptococcus pneumoniae, Neisseria meningitidis, and Haemophilus influenzae are the main etiological causes of bacterial meningitis. After trafficking across the BBB, bacterial pathogens in the brain interact with neurons, the fundamental units of Central Nervous System, and other types of glial cells. Although the specific molecular mechanism behind the interaction between such pathogens with neurons is still under investigation, it is clear that bacterial interaction with neurons and neuroinflammatory responses within the brain leads to neuronal cell death. Furthermore, clinical studies have shown indications of meningitis-caused dementia; and a variety of neurodegenerative diseases such as Alzheimer's disease, Parkinson's disease and Huntington's disease are characterized by the loss of neurons, which, unlike many other eukaryotic cells, once dead or damaged, they are seldom replaced. The aim of this review article is to provide an overview of the knowledge on how bacterial pathogens in the brain damage neurons through direct and indirect interactions, and how the neuronal damage caused by bacterial pathogen can, in the long-term, influence the onset of neurodegenerative disorders.

Keywords: bacterial infection, neuronal damage, meningitis, Streptococcus pneumoniae, dementia

\section{INTRODUCTION}

The incidence of neurological and neurodegenerative diseases has continuously increased worldwide in the last decades, with an expected rise in the coming years due to the aging of the world population. Dementia, which currently affects more than 50 million people globally, is expected to expand its incidence to over 135 million by 2050 (McManus and Heneka, 2017). However, even though genetic and/or environmental factors have been described in many of such diseases, direct causality has not been clearly established: several genetic mutations are associated with dementia, but the reasons why the pathogenesis occurs, when, and how it does, remain unclear (Patrick et al., 2019). In this regard, the interplay between neurological damage, dementia and 
pathogenic infections has been increasingly assessed during the last years. Indeed, infectious disease burden seems correlated with neurological damage and neurodegenerative progression (Strandberg et al., 2004; Katan et al., 2013). Bacterial meningitis, the inflammation of the meninges caused by infection of the brain parenchymal tissue due to several infectious agents, remains among the leading infectious diseases worldwide (Van De Beek et al., 2016). Streptococcus pneumoniae (the pneumococcus) and Neisseria meningitidis (the meningococcus) are the main causes of acute bacterial meningitis in Europe and the USA. Depending on the geographical region, mortality rates range between $20-51 \%$ and $3-10 \%$ respectively, and up to $50 \%$ of survivors present long-term neuronal sequelae, including cognitive impairments and hearing loss (Lucas et al., 2016). Haemophilus influenzae type b was the leading cause of bacterial meningitis worldwide before the introduction of vaccination; due to lack of vaccination in developing countries, it is still an important cause of meningitis in these regions (Wahl et al., 2018). On the other hand, the introduction of vaccination programs for certain serotypes of meningococci and pneumococci has dropped the incidence of bacterial meningitis in recent years. At the same time, bacterial meningitis due to serotypes that are not included in the vaccine is increasing (McIntyre et al., 2012). Furthermore, the case fatality rate remains high and the clinical outcomes are highly dependent on good health care systems (Swartz, 2004; Thigpen et al., 2011).

In this mini-review article, we will focus on how the three main etiological causes of bacterial meningitis induce both direct and indirect neuronal damage and promote neuroinflammation. Finally, we will show its burden on the population, in terms of neurological disorders and increased risk of dementia, as well as the current efforts and strategies to prevent brain damage and, ultimately, reduce the risk of neurodegenerative diseases.

\section{NEURONAL DAMAGE IN BACTERIAL MENINGITIS}

The bacterial colonization of the nasopharynx is usually an asymptomatic event (Aniansson et al., 1992; Mook-Kanamori et al., 2011); however, the bacteria can penetrate the mucosal epithelium and basal membrane causing invasive disease (Leib and Täuber, 1999). Meningitis develops if the bacteria enter the systemic circulation, penetrate the blood-brain barrier (BBB), and infect the brain, causing inflammation of the parenchyma and meninges (Iovino et al., 2016). Neuroinflammation may promote neuronal damage, which might have an unrepairable effect on neuronal circuits due to the post-mitotic state of neurons (Herrup and Yang, 2007).

\section{Direct Damage Caused by S. pneumoniae Infection}

Among the bacterial effectors responsible for neuronal damage, the cytotoxin of S. pneumoniae pneumolysin (Ply) is one of the best characterized. Ply is a $53 \mathrm{kDa}$ protein expressed by the majority of clinically-isolated S. pneumoniae and exhibits both cytolytic and immunomodulatory effects (Kalin et al., 1987). Upon release from the bacterium, Ply subunits interact in a cholesterol-dependent manner with the cell membrane causing the generation of a pore $\sim 300 \AA$ in diameter, which is cytotoxic to the cell (Mitchell and Dalziel, 2014). In patients suffering from pneumococcal meningitis, Ply was detected in the cerebrospinal fluid (CSF). Furthermore, non-surviving patients had increased Ply levels in the CSF $48 \mathrm{~h}$ after hospitalization compared to survivors, indicating the potential deleterious role of this protein on mortality (Wall et al., 2012). Although one early report on the role of Ply in meningitis affirmed that rabbits infected with a Ply deficient $S$. pneumoniae strain showed similar meningeal inflammation pathogenesis compared with rabbits infected with wild-type S. pneumoniae strain (Friedland et al., 1995), several other studies disagree with these results. In guinea pigs inoculated with $S$. pneumoniae, Ply was shown to cause cochlear damage and consequently hearing impairment (Winter et al., 1997). Additionally, both in vitro and in vivo studies affirm the cytotoxicity of Ply, as exposure of Ply to neurons caused cellular damage; and Ply deficiency, reduced virulence of the bacteria (Braun et al., 2002, 2007; Wellmer et al., 2002; Robert et al., 2008; Reißet al., 2011). The mechanism behind the Ply-induced neuronal death in vitro has been shown to be due to, at least in part, the increased intracellular levels of $\mathrm{Ca}^{2+}$, resulting in a disruption of the mitochondrial function and activation of apoptosis-induced factors (Braun et al., 2002; Stringaris et al., 2002).

Ply also mediates indirect pathological effects on brain fitness (Braun et al., 2002; Stringaris et al., 2002). First, it damages ciliary ependymal cells in the ventricles, which then reduces the ciliary beating frequency (Mohammed et al., 1999; Hirst et al., 2000). Fully functional ciliary beating is crucial for controlling the CSF volume, transportation of macromolecules, and removal of waste (Olstad et al., 2019). Thus, non-functional ciliary cells most likely contribute to the neuropathological effects in pneumococcal meningitis. Second, it interacts with immune cells in a toll-like receptors 4 (TLR 4)-independent fashion, promoting the release of pro-inflammatory cytokines (McNeela et al., 2010); and third, it induces astrocytic shrinkage, impairing synaptic functionality but also mediating easier spread of bacteria and toxins in brain regions (Förtsch et al., 2011; Hupp et al., 2012).

It was recently shown that Ply might facilitate the internalization of the pneumococcus into neurons together with the pilus-1, a protein complex with adhesin activity, exposed outside the cell wall, which has been associated with the capacity of pneumococci to interact with and invade different types of host cells (Iovino et al., 2020). More specifically, both the pilus- 1 component RrgA and Ply interact with $\beta$-actin exposed on the neuronal plasma membrane. This interaction caused disruption of the $\beta$-actin filaments with consequent neuronal cell death; an intact actin cytoskeleton was previously reported to inhibit the activation of $\mathrm{Ca}^{2+}$ influx, the finding of Ply and RrgA enhancing intracellular $\mathrm{Ca}^{2+}$ levels in neurons was likely due to the disruption of $\beta$-actin filaments (Rosado and Sage, 2000; Tabusi et al., 2021). In the case of $\operatorname{RrgA}$, the, to this date, unknown mechanism behind this process may involve its D3-domain, which has been shown to exhibit an integrin-like fold and may directly interact with $\beta$-actin filaments, altering their structure. Furthermore, the co-localization of $\beta$-actin and 
the pneumococcus, even after internalization, suggests that the bacteria use the neuronal cytoskeleton to become internalized (Tabusi et al., 2021).

Additionally, the reactive oxidative species hydrogen peroxide $\left(\mathrm{H}_{2} \mathrm{O}_{2}\right)$ is produced directly by the pneumococcus, and through its secretion causes DNA damage and epithelial cell death (Spellerberg et al., 1996; Rai et al., 2015). Indeed, primary murine neurons suffered increased apoptosis when treating them with $\mathrm{H}_{2} \mathrm{O}_{2}$, through inhibition of mechanistic target of rapamycin (mTOR) signaling (Chen et al., 2010). $\mathrm{H}_{2} \mathrm{O}_{2}$ also caused microglia apoptosis, possibly synergically together with Ply (Braun et al., 2002). In human brain endothelial cells (hBMECs), Ply and $\mathrm{H}_{2} \mathrm{O}_{2}$ caused apoptosis independently of TLR2 and TLR4 signaling (Bermpohl et al., 2005).

$N$. meningitidis is also known to produce direct damage and cell death to several cell types, but to our knowledge, no studies have reported direct damage to neurons. Two of the most important virulence factors in N. meningitidis are PorB and type IV pilus. While the pilus mediates attachment to the plasma membrane, both have been shown to trigger an influx of $\mathrm{Ca}^{2+}$ in epithelial cells; in the case of PorB, this has been directly linked with apoptosis (Müller et al., 1999; Tzeng and Stephens, 2000). Due to the relevance of $\mathrm{Ca}^{2+}$ concentration in cells and, as these processes are evolutionary conserved, we can hypothesise that they may also mediate neuronal damage. However, direct experimental data on neurons is required to confirm it.

\section{Indirect Neuronal Damage: Neuroinflammation in Bacterial Meningitis}

In several neurodegenerative diseases, including dementia, chronic neuroinflammation is associated with the disease and is also importantly observed prior to neuronal degeneration (Frank-Cannon et al., 2009). While, in the initial phases of the disease, neuroinflammation and the following clearance of unwanted pathogens or non-degradable proteins is desirable, it also mediates harmful effects on the brain environment both in the short and long-term. Neuroinflammation causes the release of several cytotoxic compounds, including reactive oxidative species and nitric oxide, which can stimulate the release of pro-apoptotic compounds, ultimately leading to apoptosis of neurons and other brain resident cells (Lyman et al., 2014). Because neurons are in a post-mitotic state, this has potential deleterious effects as it contributes to neuronal degradation without future replacement of cells (Herrup and Yang, 2007). It is known that bacterial meningitis-induced neuroinflammation causes neuronal degradation (Kim, 2003). This has the potential to be an increased risk factor for the development of neurological diseases, including dementia.

The major players of neuroinflammation are the microglia, the macrophages of the brain, and infiltrating peripheral immune cells (Becher et al., 2017). The use of immunosuppressants in therapy against meningitis has proven to be beneficial for patients, indicating that the pro-inflammatory response itself mediates some of the most pathological effects in the brain (De Gans and van de Beek, 2002). The bacterial invasion of the brain begins with the traversal through the protective $\mathrm{BBB}$, which is composed of brain microvascular endothelial cells, astrocytes, and pericytes, and regulates the movement of active agents, both molecules and cells, in and out the brain (Kim, 2008). Pathogens cross the BBB by three main mechanisms: transcellular migration, para-cellular migration, and internalized in macrophages in a "trojan horse" way (Barichello et al., 2013). The high mortality rate in meningitis patients (even after the introduction of antibiotic treatment) has been linked to inefficiency in the clearance of the bacteria from the brain and the infiltration of peripheral immune cells that cause increased cranial pressure (Van De Beek et al., 2002; Liechti et al., 2015). The microglial cells become activated in response to the bacterial presence and induce a phagocytic response in order to clear the infection. Additionally, bacterial components are recognized, causing an inflammatory response and release of chemo and cytokines. In synergy with chemoattractants produced by other brain resident cells, this causes the infiltration of peripheral immune cells (Barichello et al., 2016). On hospitalization, bacterial meningitis patients present a leaky $\mathrm{BBB}$, a feature observed in other neurological diseases that is known to be related to the infiltration of peripheral immune cells and contributes to the neuroinflammation (Sharief et al., 1992; Stolp and Dziegielewska, 2009). Although lack of neutrophil infiltration was shown to cause more severe disease in experimental bacterial meningitis, this was attributed to the reduced clearance of the bacteria from the brain (Aust et al., 2018). This points out the importance of the balance between beneficial and deleterious neuroinflammation. While studies on the role of peripheral immune cells in bacterial meningitis is scarce, the role of microglia has been thoroughly reviewed elsewhere (Barichello et al., 2016; Thorsdottir et al., 2019). In this review article, we will focus on the mechanism behind the innate immune response to the respective bacteria.

Among biological systems for immune response, TLRs are known to recognize bacterial compounds such as lipoteichoic acid, peptidoglycans, and lipopolysaccharides, but also other bacterial components can interact with these receptors (Schröder et al., 2003). While different TLRs expression varies between brain cells, most of them use the same intracellular adapter protein, myeloid differentiation factor 88 (Myd88), as a transducer (Takeda et al., 2003; Kielian, 2009). This factor interacts with receptor-associated kinase-4, which in turn mediates the activation of the tumor necrosis factor (TNF) receptor-associated factor family, the translocation of nuclear factor (NF)- $\kappa \mathrm{B}$ to the nucleus, and the activation of a wide range of genes implicated in the elicitation of the immune response, both in terms of lymphocyte activation and in the production of cytokines and chemokines (Kawasaki and Kawai, 2014). This mechanism has been observed in innate immune cells, including microglia, but also in other brain resident cells (Kopitar-Jerala, 2015). Lymphocytes, on the other hand, have been shown to infiltrate the brain tissues, thus contributing to the neuroinflammatory response (Hoffmann et al., 2015).

Stimulation of peripheral blood mononuclear cells (PBMCs) with $S$. pneumoniae, $N$. meningitidis, or $H$. influenzae caused a significantly increased expression of NF- $\kappa$ B and the cytokines interleukin (IL)-6, IL-8, and TNF- $\alpha$ compared to untreated 
PBMCs. Interestingly, N. meningitidis induced the highest TNF$\alpha$ expression (Mogensen, 2006). H. influenzae has been shown to interact with both TLR2 and TLR4 (Wang et al., 2002; Galdiero et al., 2004). Porin on the outer membrane of $H$. influenzae type $\mathrm{B}$ activated monocytes by interacting with TLR2, dependently on the co-expression of TLR2 and CD14 on the surface, and the downstream signaling protein Myd88 (Galdiero et al., 2004). Furthermore, lipooligosaccharides (LOS) activated TLR4, but LOS with reduced acetylation activated TLR2, indicating that, through slight modification, bacteria can interact with different receptors (Lorenz et al., 2005). N. meningitidis LOS is also a major inducer of inflammation and a tenfold reduction in TNF- $\alpha$ levels has been reported in LOS mutant compared to the wild-type strain (Alison et al., 2001). Additionally, capsule polysaccharides have been shown to cause the release of TNF- $\alpha$, IL- 6 , IL- 8 , and CXCL10, mediated through TLR2 and TLR4/MD-2 pathways (Zughaier, 2011). Meningothelial cells release cytokines when in contact with the meningococcus, with IL-6, CXCL10, and CCL5 levels reduced by up to $90 \%$ in TLR4 knockouts (Royer et al., 2013). PorB binds to TLR2/TLR1 causing increased activation of NF- $\kappa \mathrm{B}$ as measured by IL-8 induced levels (Massari et al., 2006). Finally, S. pneumoniae Ply has been shown to induce inflammation in a TLR4 dependent, but also independent pathway, while lipoteichoic acid interacts with the TLR2 (Malley et al., 2003; Schröder et al., 2003; McNeela et al., 2010). Furthermore, TLR1/2 levels were increased upon S. pneumoniae stimulation, and knockout of TLR9 caused mice to be more susceptible to disease; implementing also these TLR receptors in the innate immune sensing of S. pneumoniae (Schmeck et al., 2006; Albiger et al., 2007).

Bacterial compounds also elicit a cellular response through intracellular mechanisms. In this regard, NOD-like receptors are intracellular receptors whose major downstream activating pathways are the NF- $\mathrm{B}$ and the mitogen-activated protein kinase (MAPK) pathways, resulting in increased pro-inflammatory cytokine production (Chen et al., 2009). Peptidoglycans expressed on the bacterial cell surface are recognized by the intercellular receptor NOD2 (Sorbara and Philpott, 2011). In mpneumococcal-induced meningitis, both microglia and astrocyte recognize $S$. pneumoniae components through the NOD2 receptor, causing increased nuclear translocation of NF- $\kappa$ B and release of IL- 6 and TNF- $\alpha$ from both cell types. Furthermore, this has been associated with elevated astrogliosis and demyelination in the corpus callosum (Liu et al., 2010). Interestingly, this has also been reported in $N$. meningitidis-induced meningitis (Chauhan et al., 2009). Clearly, this indicates the central role of the NOD2 receptor in the contribution to a deleterious inflammation response that results in neuronal damage in bacterial meningitis. Monocytes treated with LOS also show increased NOD2 expression (Choi et al., 2014). Peptidoglycans released by meningococci are detected by NOD1 and induce an inflammatory response to these (Woodhams et al., 2013). Taken together these results provide evidence for the role of NOD-like receptors in the meningitis neuroinflammatory state. Three NOD-like receptor protein families (NLRP1, NLRP3, and NLRC4) can assemble to generate an inflammasome, leading to caspase- 1 activation and cleaving of the precursors of IL-1 $\beta$ and IL-18 into their active counterparts (Gross et al., 2011). NLRP3 has been shown to be an important factor in the pathology of meningitis (Hoegen et al., 2011) In pneumococcal-induced meningitis, the production of interferon (IFN)- $\gamma$ was dependent on the protein ASC, which is an adaptor protein for multiple inflammasomes (Mitchell et al., 2012). Ply is also able to induce the expression of the inflammasome, independently of TLR4 interaction (McNeela et al., 2010; Hoegen et al., 2011).

In the extracellular milieu, cytokines modulate and regulate the inflammatory response on target cells and are important for the clearance of unwanted products, but also for inhibition of excessive immune responses (Kany et al., 2019). In bacterial meningitis, the cytokines released are dependent on the stimuli, signaling receptor and cell type. It has been shown that IL-1 $\beta$ and IL-18 levels are upregulated during bacterial meningitis and, specifically, IL-1 $\beta$ levels are correlated with leukocyte levels in the CSF and neuronal sequelae in patients (Mustafa et al., 1989; Fassbender et al., 1999). TNF- $\alpha$ expression has been shown to be upregulated in the brain after pneumococcal-induced meningitis (Barichello et al., 2009). When comparing meningococcalinduced bacteremia and meningitis in patients, TNF- $\alpha$ levels were significantly higher in the latter (Waage et al., 1989). Microglia, astrocytes and neurons express TNF- $\alpha$ receptors (TNFR), with TNFR1 being the most abundant (Barichello et al., 2009). Through this receptor, TNF- $\alpha$ can induce apoptosis of cells in already stressed cells; therefore, an adjuvant therapy against TNF- $\alpha$ could be relevant for treatment against bacterial meningitis, and indeed this has been shown to attenuate neuronal death in rats (Leib, 2001; Bhardwaj and Aggarwal, 2003). hBMECs have increased IL-8 and IL-6 production compared to peripheral endothelial cells when exposed to $N$. meningitidis. These cytokines are important for the activation of the immune system and indicate that the hBMECs themselves contribute to the increased pro-inflammatory milieu in the brain (Dick et al., 2017). Both direct and indirect mechanisms of neuronal damage in bacterial meningitis have been summarized in Figure 1.

\section{INFECTION BURDEN AND THE EPIDEMIOLOGY OF DEMENTIA}

As stated in the introduction, the relevance of the infectious etiology has been increasingly stressed in several neurodegenerative diseases, such as Alzheimer's disease (AD; Sochocka et al., 2017), Parkinson's disease (PD; Brudek, 2019), and Rapidly Progressive Dementia (Geschwind, 2016). However, a clear relationship between dementia and infectious alterations of normal physiology is difficult to establish for several reasons. Sepsis, on the other hand, a grave condition which can be caused by several pathogens, is known to produce severe BBB dysfunction (Barichello et al., 2021), microglial activation ( $\mathrm{Li}$ et al., 2020), acute neuroinflammation, brain injury and cerebral dysfunction (Meneses et al., 2019; Gu et al., 2021), and long-term cognitive and functional impairments (Brown, 2019; Rengel et al., 2019). This is also true for bacterial meningitis, especially in the case of neonates (Heath et al., 2011) and young infants (Hsu et al., 2018). 


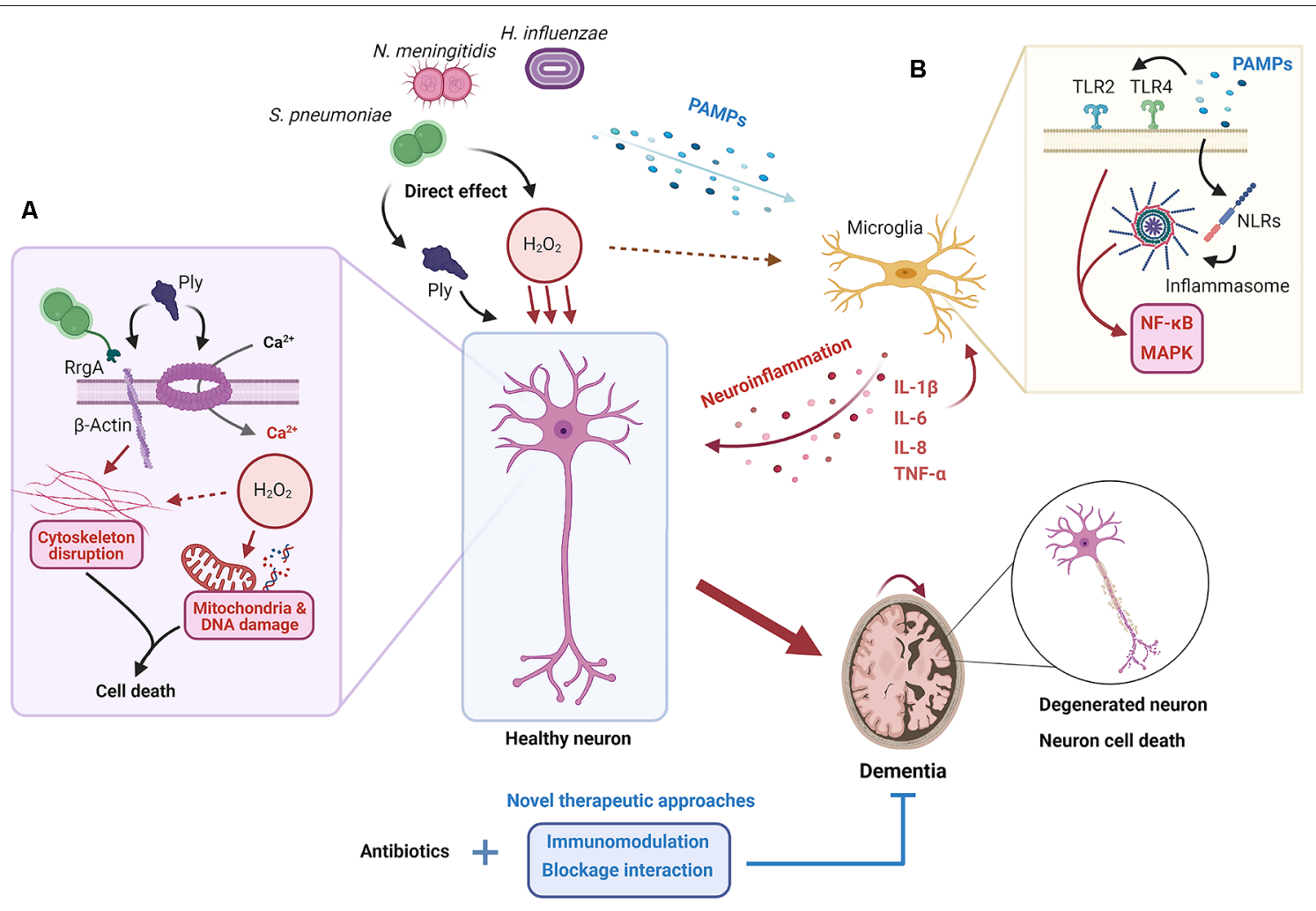

FIGURE 1 | Proposed mechanisms for neuronal damage during bacterial meningitis. When the pathogens S. pneumoniae, N. meningitidis, and H. influenzae invade the brain, both the action of their virulence factors and the elicited neuroinflammatory response cause neuronal damage and death. (A) Pores in the neuron plasma membrane formed by pneumolysin (Ply), released by $\mathrm{S}$. pneumoniae, result in the influx of extracellular $\mathrm{Ca}^{2+}$. At the same time, the interaction between $\beta$-actin, exposed outside the plasma membrane, with Ply and RrgA causes the disruption of the actin cytoskeleton. This, coupled with the release of $\mathrm{H}_{2} \mathrm{O}_{2}$, oxidative outburst, and subsequent mitochondrial and DNA damage, results in neuronal death. (B) Several pathogen-associated molecular patterns (PAMPs) are recognized by microglia through receptors such as TLRs and NLRs, which results in the activation of nuclear factor (NF)-KB and the mitogen-activated protein kinase (MAPK) pathway and the release of pro-inflammatory cytokines and other mediators, and the recruitment of inflammatory cells. The establishment of a neuroinflammatory state inside the brain leads to neuronal death through different mechanisms such as tumor necrosis factor (TNF)- $\alpha$ overproduction or oxidative outburst. Ultimately, neuronal death results in neurological sequelae and potential long-term dementia; something that may be prevented if current antibiotic treatments are coupled with new therapeutic approaches based on immunomodulation and/or blockage of direct interaction between bacteria and cells.

In patients with $\mathrm{AD}$ both the onset and the progression of the disease has been associated with a history of infection in the patient's life; in particular, the incidence of pneumonia, as well as respiratory and urinary tracts infections, has been shown to be higher in $\mathrm{AD}$ patients, traditionally considered a consequence of the disease, but can also be related to its onset (Kountouras et al., 2006; Natalwala et al., 2008; Miklossy, 2011; Too et al., 2021). Delirium, on the other hand, often caused by CNS infection, is correlated with an acceleration in the progression towards dementia (McManus and Heneka, 2017). Dunn and colleagues also found an association between dementia and infectious disease in a case-control study (Dunn et al., 2005). Bacterial periodontitis, a common ailment in the elderly, has also been shown to correlate with cognitive decline and $\mathrm{AD}$ (Ide et al., 2016). Eradication of Helicobacter pylori infection has been hinted to be beneficial in hampering $\mathrm{AD}$ progression (Kountouras et al., 2009). Leprosy has also been linked to dementia (Su et al., 2012), though anti-leprosy drugs do not appear to have an effect in the prevention of $\mathrm{AD}$ neurotoxicity (Endoh et al., 1999). This relationship between the CNS and microbiological agents does not restrict itself to infectious pathogens, however. The gut microbiota now seems to play an important homeostatic role in the brain, as shown both in human (Paley, 2019) and mice, in which the Apolipoprotein E genotype -the strongest prevalent risk factor for $\mathrm{AD}$ development- has been sharply associated with specific gut microbiome profiles (Tran et al., 2019). This has led to the definition of a braingut-microbiota axis in which d-glutamate metabolized by the gut may significantly contribute to or hamper the progression of AD (Chang et al., 2020). Also, a 12-week supplementation of Bifidobacterium breve A1 has shown a promising effect in preserving cognitive function in elderly subjects with memory loss complaints (Kobayashi et al., 2019).

Evidence of the relationship between infectious burden and neurodegeneration is not restricted to AD. A case-control study by Vlajinac and colleagues showed a correlation between PD and several infectious agents such as $H$. pylori (Bjarnason et al., 2005; Shen et al., 2017; Dardiotis et al., 2018). H. pylori infection has also been associated with multiple sclerosis (MS), as a putative protective factor (Jaruvongvanich et al., 2016; Yao 
et al., 2016). In MS, an infection by Chlamydia pneumoniae is considered a risk factor (McKay et al., 2015). Lastly and interestingly, the risk for schizophrenia is enhanced in offspring exposed to microbiological infections (Brown and Susser, 2002), and in bacterial-infected pregnant women's offspring (Sørensen et al., 2008).

Bacterial meningitis is well known to potentially produce neuronal damage even after pathogen clearance and good prognosis. In 2002, Van de Beek and colleagues reported the presence of long-term cognitive sequelae in patients who had recovered well after pneumococcal meningitis; $27 \%$ presented significative cognitive slowness (Van De Beek et al., 2002). Indeed, a later study showed similar cognitive disabilities in patients with moderate disability after bacterial meningitis than patients with good recovery, hinting at a similar risk for further long-term neurological damage (Weisfelt et al., 2006). Later reports have confirmed the neuropsychological sequelae of bacterial meningitis, specifically cognitive slowness, epilepsy, and hearing loss, but also affected learning and memory functions, poorer performance in executive functions, language, and verbal tests (Schmidt et al., 2006; Hoogman et al., 2007; Christie et al., 2017). The risk of at least one major sequelae (cognitive deficit, bilateral hearing loss, motor deficit, seizures, visual impairment, hydrocephalus) has been estimated at $13 \%$, this percentage rises to almost $25 \%$ in pneumococcal meningitis (Grimwood et al., 1995; Edmond et al., 2010). Neonatal pneumococcal meningitis leads to cognitive impairment in 30-52\% of surviving patients (Barichello et al., 2013). Furthermore, $S$. pneumoniae-induced meningitis in childhood and adolescence has been linked with long-term neurological damage. After $\geq 14$ years of pneumococcal meningitis diagnosis and treatment, patients showed significantly lower full scale and verbal IQ, numeracy or school functioning; $14 \%$ of them presented partial or profound hearing impairment (Christie et al., 2011). Severe bacterial meningitis, which can cause cerebral infarction, cerebritis, subdural empyema, cerebral abscess or intracerebral bleeding, can lead to grave neurological sequelae such as short-term (Naito et al., 2010) or even long-term cognitive impairment (Singhi et al., 2007; Lucas et al., 2016), epilepsy, and dementia (Kamei, 2016), with critically worse prognosis in the case of neonatal bacterial meningitis (Baud and Aujard, 2013). This epidemiological picture correlates with brain injury observed in bacterial meningitis patients. Vasculitis, intravascular coagulation, and reduced blood flow cause ischemic, necrotic brain injury in the cortex; at the same time, an apoptotic burst has been described in the dentate gyrus of the hippocampus, as a result of a process which involves multiple effects induced by bacteria, their components, and the host immune response (Liechti et al., 2015).

\section{TRANSLATIONAL APPROACHES TO PREVENT INFECTION-DERIVED NEURONAL DAMAGE}

By means of direct interaction with cells and/or neuroinflammation, infections in the brain have the potential to provoke neurological sequelae, which may, in the long-term, develop into dementia. Thus, clearance of the infection is not enough to provide a full recovery to patients suffering from different kind of illnesses; novel therapeutic approaches that can either prevent bacterial invasion of the brain, or block bacterial interaction with brain cells, especially neurons, must be developed to reduce the chances of dementia onset in the elderly. To begin with, it is important to clearly identify the bacterial virulence factors that promote brain invasion, activation of the immune system, and neuron cell death.

In pneumococcal meningitis, for instance, polymeric immunoglobulin receptor (pIgR) and platelet endothelial cell adhesion molecule (PECAM-1) has been identified as the receptors on the $\mathrm{BBB}$ endothelial cells that mediate invasion of S. pneumoniaeinto the brain (Iovino et al., 2016); a combination of anti-pIgR and PECAM- 1 antibodies with $\beta$-lactam antibiotics have proven to minimize pneumococci invasion of the brain, a proof of concept of a successful blockade of host-pathogen interaction in vivo (Iovino et al., 2017, 2018). However, the infection itself usually disrupts the integrity of the $\mathrm{BBB}$, an advantage for antibiotics to reach the brain but a problem if the approach is to block pathogens crossing the barrier, as most therapies will aim at the aftermath of an infection (Al-Obaidi and Desa, 2018). An alternative may consist in the development of so-called smart carriers, such as bioengineered extracellular vesicles (Saint-Pol et al., 2020; Shahjin et al., 2020), modified liposomes (Zhang et al., 2019) or synthetic nanoparticles (Zhou et al., 2018).

With or without an efficient brain delivery device, biological processes must be correctly targeted to prevent neuronal damage. Among promising findings, brain-derived neurotrophic factor and melatonin were thought to protect against brain injury, improve hearing, and reduce neuronal death in pediatric bacterial meningitis (Grandgirard and Leib, 2006). In terms of modulating the neuroinflammatory process, the anti-inflammatory and immunosuppressive effects of corticosteroids have been well known for decades. In a metaanalysis, corticosteroid administration in bacterial meningitis patients has been shown to prevent hearing loss and shortterm neurological sequelae in high-income countries. This effect, however, seems strain-specific and is not observed in low-income countries (Brouwer et al., 2015). Reducing the neutrophil recruitment to the brain, on the other hand, through modulation of apoptosis may be a potential new way to reduce neuronal damage (Principi and Esposito, 2020). Antibiotics themselves contribute to the inflammatory response if they have a bacteriolytic activity, which releases highly inflammatory lysis products (Kietzman and Tuomanen, 2019). Using bactericidal but non-bacteriolytic antibiotics such as daptomycin may bypass this problem (Principi and Esposito, 2020). The adjunction of daptomycin in the treatment of bacterial meningitis has recently proven its therapeutic potential in vitro (Maldiney et al., 2021) and it is the subject of an ongoing clinical trial to improve the prognosis and survival of pneumococcal meningitis (AddaMAP, NCT03480191). Finally, due to its relevance in neuroinflammation and brain disease, and its implication in neuron cell death, inflammasome modulation 
is considered a promising target in the context of bacterial meningitis (Walsh et al., 2014) and neurodegenerative diseases (Heneka et al., 2018).

Ultimately, targeting the direct interaction between pathogenic agents and neurons maybe a third alternative, though many of the molecular mechanisms involved in such interactions are focused on immune cells or the BBB, poorly characterized, or not known. In S. pneumoniae bacterial meningitis, we have recently shown that the bacteria attachment and invasion of the neuron is mediated through RrgA and Ply interaction with exposed $\beta$-actin on the plasma membrane (Tabusi et al., 2021). Preventing or blocking altogether this kind of direct interactions between neurons and infectious agents may well provide novel translational approaches to prevent brain damage and dementia.

\section{CONCLUDING REMARKS}

While the deleterious effects of bacterial infections on neurological function are now clear in several models of disease, the sequelae of such infections, from hearing loss to motor and cognitive dysfunctions remain highly prevalent. In pneumococcal-induced meningitis, more systematic and

\section{REFERENCES}

Al-Obaidi, M. M. J., and Desa, M. N. M. (2018). Mechanisms of blood brain barrier disruption by different types of bacteria and bacterial-host interactions facilitate the bacterial pathogen invading the brain. Cell. Mol. Neurobiol. 38, 1349-1368. doi: 10.1007/s10571-018-0609-2

Albiger, B., Sofia, D., Andreas, S., Florian, W., Katharina, B., Hiroaki, K., et al. (2007). Toll-like receptor 9 acts at an early stage in host defence against pneumococcal infection. Cell. Microbiol. 9, 633-644. doi: 10.1111/j.1462-5822. 2006.00814.x

Alison, D., Abdillahi, F., Steeghs, L. P., and Robert, S. (2001). A lipopolysaccharidedeficient mutant ofneisseria meningitidiselicits attenuated cytokine release by human macrophages and signals via Toll-like receptor (TLR) 2 but not via TLR4/MD2. J. Infect. Dis. 183, 89-96. doi: 10.1086/317647

Aniansson, G., Alm, B., Andersson, B., Larsson, P., Nylen, O., Peterson, H., et al. (1992). Nasopharyngeal colonization during the first year of life. J. Infect. Dis. 165, S38-S42. doi: 10.1093/infdis/165-supplement_1-s38

Aust, V., Eugenia, K., Stephanie, A., Nicole, S., Markus, K., Matthias, B. S., et al. (2018). Lack of chemokine (C-C motif) ligand 3 leads to decreased survival and reduced immune response after bacterial meningitis. Cytokine 111, 246-254. doi: 10.1016/j.cyto.2018.09.001

Barichello, T., Dos Santos, I., Savi, G. D., Florentino, A. F., Silvestre, C., Comim, C. M., et al. (2009). Tumor necrosis factor alpha (TNF- $\alpha$ ) levels in the brain and cerebrospinal fluid after meningitis induced by Streptococcus pneumoniae. Neurosci. Lett. 467, 217-219. doi: 10.1016/j.neulet.2009.10.039

Barichello, T., Fagundes, G. D., Generoso, J. S., Elias, S. G., Simões, L. R., Teixeira, A. L., et al. (2013). Pathophysiology of neonatal acute bacterial meningitis. J. Med. Microbiol. 62, 1781-1789. doi: 10.1099/jmm.0.059840-0

Barichello, T., Generoso, J. S., Collodel, A., Petronilho, F., and Dal-Pizzol, F. (2021). The blood-brain barrier dysfunction in sepsis. Tissue Barriers 9:1840912. doi: 10.1080/21688370.2020.1840912

Barichello, T., Generoso, J. S., Simões, L. R., Goularte, J. A., Petronilho, F., Saigal, P., et al. (2016). Role of microglial activation in the pathophysiology of bacterial meningitis. Mol. Neurobiol. 53, 1770-1781. doi: 10.1007/s12035-0159107-4

Baud, O., and Aujard, Y. (2013). Neonatal bacterial meningitis. Handb. Clin. Neurol. 112, 1109-1113. doi: 10.1016/B978-0-444-52910-7. 00030-1 epidemiological studies are required in order to assess the importance of different virulent factors such as RrgA or Ply, whose mechanisms of action in neurons could explain much of the short-term and long-term neuronal damage observed in recovered patients (Tabusi et al., 2021). Additionally, long-term epidemiological studies of survivors from bacterial meningitis may clarify the relationship between brain infection and the onset of dementia. Finally, treatments targeting neuroinflammation and neuronal damage may prove useful to prevent the development of neurodegenerative diseases.

\section{AUTHOR CONTRIBUTIONS}

KF and MT-V wrote the manuscript draft. FI designed the overall theme and provided supervision. All authors contributed to the article and approved the submitted version.

\section{FUNDING}

We thank all the major funding that has supported this study: Vetenskapsrådet (The Swedish Research Council), the Bjarne Ahlström Foundation, the Karolinska Institutet Faculty Board, and Fredrik and Ingrid Thuring Foundation.

Becher, B., Spath, S., and Goverman, J. (2017). Cytokine networks in neuroinflammation. Nat. Rev. Immunol. 17, 49-59. doi: 10.1038/nri.2016.123

Bermpohl, D., Halle, A., Freyer, D., Dagand, E., Braun, J. S., Bechmann, I., et al. (2005). Bacterial programmed cell death of cerebral endothelial cells involves dual death pathways. J. Clin. Invest. 115, 1607-1616. doi: 10.1172/JCI 23223

Bhardwaj, A., and Aggarwal, B. B. (2003). Receptor-mediated choreography of life and death. J. Clin. Immunol. 23, 317-332. doi: 10.1023/a:102531 9031417

Bjarnason, I. T., Charlett, A., Dobbs, R. J., Dobbs, S. M., Ibrahim, M. A., Kerwin, R. W., et al. (2005). Role of chronic infection and inflammation in the gastrointestinal tract in the etiology and pathogenesis of idiopathic parkinsonism. Part 2: response of facets of clinical idiopathic parkinsonism to Helicobacter pylori eradication. A randomized, double-blind, placebocontrolled efficacy stud. Helicobacter 10, 276-287. doi: 10.1111/j.1523-5378. 2005.00330.x

Braun, J. S., Hoffmann, O., Schickhaus, M., Freyer, D., Dagand, E., Bermpohl, D., et al. (2007). Pneumolysin causes neuronal cell death through mitochondrial damage. Infect. Immun. 75, 4245-4254. doi: 10.1128/IAI.00031-07

Braun, J. S., Sublett, J. E., Freyer, D., Mitchell, T. J., Cleveland, J. L., Tuomanen, E. I., et al. (2002). Pneumococcal pneumolysin and $\mathrm{H}_{2} \mathrm{O}_{2}$ mediate brain cell apoptosis during meningitis. J. Clin. Invest. 109, 19-27. doi: 10.1172/JCI12035

Brouwer, M. C., McIntyre, P., Prasad, K., and Van De Beek, D. (2015). Corticosteroids for acute bacterial meningitis. Cochrane Database Syst. Rev. 2015:Cd004405. doi: 10.1002/14651858.CD004405.pub5

Brown, A. S., and Susser, E. S. (2002). In utero infection and adult schizophrenia. Ment. Retard. Dev. Disabil. Res. Rev. 8, 51-57. doi: 10.1002/mrdd.10004

Brown, G. C. (2019). The endotoxin hypothesis of neurodegeneration. J. Neuroinflammation 16:180. doi: 10.1186/s12974-019-1564-7

Brudek, T. (2019). Inflammatory bowel diseases and Parkinsons disease. J. Parkinsons Dis. 9, S331-S437.s44. doi: 10.3233/JPD-191729

Chang, C. H., Lin, C. H., and Lane, H. Y. (2020). D-glutamate and gut microbiota in Alzheimers disease. Int. J. Mol. Sci. 21:2676. doi: 10.3390/ijms21082676

Chauhan, V. S., Sterka, D. G., Furr, S. R., Young, A. B., and Marriott, I. (2009). NOD2 plays an important role in the inflammatory responses of microglia and astrocytes to bacterial CNS pathogens. Glia 57, 414-423. doi: 10.1002/glia. 20770 
Chen, G., Shaw, M. H., Kim, Y.-G., and Nuñez, G. (2009). NOD-like receptors: role in innate immunity and inflammatory disease. Annu. Rev. Pathol. 4, 365-398. doi: 10.1146/annurev.pathol.4.110807.092239

Chen, L., Xu, B., Liu, L., Luo, Y., Yin, J., Zhou, H., et al. (2010). Hydrogen peroxide inhibits mTOR signaling by activation of AMPK $\alpha$ leading to apoptosis of neuronal cells. Lab. Invest. 90:449. doi: 10.1038/labinvest.2010.36

Choi, J., Cox, A. D., Li, J., McCready, W., and Ulanova, M. (2014). Activation of innate immune responses by haemophilus influenzae lipooligosaccharide. Clin. Vaccine Immunol. 21, 769-776. doi: 10.1128/CVI.00063-14

Christie, D., Rashid, H., El-Bashir, H., Sweeney, F., Shore, T., Booy, R., et al. (2017). Impact of meningitis on intelligence and development: a systematic review and meta-analysis. PLoS One 12:e0175024. doi: 10.1371/journal.pone. 0175024

Christie, D., Viner, R. M., Knox, K., Coen, P. G., Wang, H., El Bashir, H., et al. (2011). Long-term outcomes of pneumococcal meningitis in childhood and adolescence. Eur. J. Pediatr. 170, 997-1006. doi: 10.1007/s00431-010 $-1390-5$

Dardiotis, E., Tsouris, Z., Mentis, A. A., Siokas, V., Michalopoulou, A., Sokratous, M., et al. (2018). H. pylori and Parkinsons disease: meta-analyses including clinical severity. Clin. Neurol. Neurosurg. 175, 16-24. doi: 10.1016/j. clineuro.2018.09.039

De Gans, J., and van de Beek, D. (2002). Dexamethasone in adults with bacterial meningitis. N. Engl. J. Med. 347, 1549-1556. doi: 10.1056/NEJMoa0 21334

Dick, J., Hebling, S., Becam, J., Taha, M.-K., and Schubert-Unkmeir, A. (2017). Comparison of the inflammatory response of brain microvascular and peripheral endothelial cells following infection with Neisseria meningitidis. Pathogens Dis. 75:ftx038. doi: 10.1093/femspd/ftx038

Dunn, N., Mullee, M., Perry, V. H., and Holmes, C. (2005). Association between dementia and infectious disease: evidence from a case-control study. Alzheimer Dis. Assoc. Disord. 19, 91-94. doi: 10.1097/01.wad.0000165511.52746.1f

Edmond, K., Clark, A., Korczak, V. S., Sanderson, C., Griffiths, U. K., Rudan, I., et al. (2010). Global and regional risk of disabling sequelae from bacterial meningitis: a systematic review and meta-analysis. Lancet Infect. Dis. 10, 317-328. doi: 10.1016/S1473-3099(10)70048-7

Endoh, M., Kunishita, T., and Tabira, T. (1999). No effect of anti-leprosy drugs in the prevention of Alzheimers disease and beta-amyloid neurotoxicity. J. Neurol. Sci. 165, 28-30. doi: 10.1016/s0022-510x(99)00057-x

Fassbender, K., Mielke, O., Bertsch, T., Muehlhauser, F., Hennerici, M., Kurimoto, M., et al. (1999). Interferon- $\gamma$-inducing factor (IL-18) and interferon- $\gamma$ in inflammatory CNS diseases. Neurology 53, 1104-1104. doi: 10.1212/wnl.53.5.1104

Förtsch, C., Hupp, S., Ma, J., Mitchell, T. J., Maier, E., Benz, R., et al. (2011). Changes in astrocyte shape induced by sublytic concentrations of the cholesterol-dependent cytolysin pneumolysin still require pore-forming capacity. Toxins 3, 43-62. doi: 10.3390/toxins3010043

Frank-Cannon, T. C., Alto, L. T., McAlpine, F. E., and Tansey, M. G. (2009). Does neuroinflammation fan the flame in neurodegenerative diseases? Mol. Neurodegener. 4:47. doi: 10.1186/1750-1326-4-47

Friedland, I. R., Paris, M. M., Hickey, S., Shelton, S., Olsen, K., Paton, J. C., et al. (1995). The limited role of pneumolysin in the pathogenesis of Pneumococcal meningitis. J. Infect. Dis. 172, 805-809. doi: 10.1093/infdis/172.3.805

Galdiero, M., Galdiero, M., Finamore, E., Rossano, F., Gambuzza, M., Catania, M. R., et al. (2004). Haemophilus influenzae porin induces toll-like receptor 2-mediated cytokine production in human monocytes and mouse macrophages. Infect. Immun. 72, 1204-1209. doi: 10.1128/iai.72.2.1204-1209. 2004

Geschwind, M. D. (2016). Rapidly progressive dementia. Continuum 22, 510-537. doi: 10.1212/CON.0000000000000319

Grandgirard, D., and Leib, S. L. (2006). Strategies to prevent neuronal damage in paediatric bacterial meningitis. Curr. Opin. Pediatr. 18, 112-118. doi: 10.1097/01.mop.0000193292.09894.b7

Grimwood, K., Anderson, V. A., Bond, L., Catroppa, C., Hore, R. L., Keir, E. H., et al. (1995). Adverse outcomes of bacterial meningitis in school-age survivors. Pediatrics 95, 646-656.

Gross, O., Thomas, C. J., Guarda, G., and Tschopp, J. (2011). The inflammasome: an integrated view. Immunol. Rev. 243, 136-151. doi: 10.1111/j.1600-065X. 2011.01046.x
Gu, M., Mei, X. L., and Zhao, Y. N. (2021). Sepsis and cerebral dysfunction: BBB damage, neuroinflammation, oxidative stress, apoptosis and autophagy as key mediators and the potential therapeutic approaches. Neurotox Res. 39, 489-503. doi: 10.1007/s12640-020-00270-5

Heath, P. T., Okike, I. O., and Oeser, C. (2011). "Neonatal Meningitis: Can We Do Better?" in Hot Topics in Infection and Immunity in Children VIII, eds A. Finn and A. J. Pollard (New York, NY: Springer).

Heneka, M. T., McManus, R. M., and Latz, E. (2018). Inflammasome signalling in brain function and neurodegenerative disease. Nat. Rev. Neurosci. 19, 610-621. doi: 10.1038/s41583-018-0055-7

Herrup, K., and Yang, Y. (2007). Cell cycle regulation in the postmitotic neuron: oxymoron or new biology? Nat. Rev. Neurosci. 8, 368-378. doi: $10.1038 / \mathrm{nrn} 2124$

Hirst, R. A., Rutman, A., Sikand, K., Andrew, P. W., Mitchell, T. J., OCallaghan, C., et al. (2000). Effect of pneumolysin on rat brain ciliary function: comparison of brain slices with cultured ependymal cells. Pediatr. Res. 47, 381-384. doi: 10.1203/00006450-200003000-00016

Hoegen, T., Tremel, N., Klein, M., Angele, B., Wagner, H., Kirschning, C., et al. (2011). The NLRP3 inflammasome contributes to brain injury in pneumococcal meningitis and is activated through atp-dependent lysosomal cathepsin b release. J. Immunol. 187, 5440-5451. doi: 10.4049/jimmunol. 1100790

Hoffmann, O., Rung, O., Held, J., Boettcher, C., Prokop, S., Stenzel, W., et al. (2015). Lymphocytes modulate innate immune responses and neuronal damage in experimental meningitis. Infect. Immun. 83, 259-267. doi: 10.1128/IAI.02682-14

Hoogman, M., Van De Beek, D., Weisfelt, M., De Gans, M., and Schmand, B. (2007). Cognitive outcome in adults after bacterial meningitis. J. Neurol. Neurosurg. Psychiatry 78, 1092-1096. doi: 10.1136/jnnp.2006.110023

Hsu, M.-H., Hsu, J.-F., Kuo, H.-C., Lai, M.-Y., Chiang, M.-C., Lin, Y.-J., et al. (2018). Neurological complications in young infants with acute bacterial meningitis. Front. Neurol. 9:903. doi: 10.3389/fneur.2018.00903

Hupp, S., Heimeroth, V., Wippel, C., Förtsch, C., Ma, J., Mitchell, T. J., et al. (2012). Astrocytic tissue remodeling by the meningitis neurotoxin pneumolysin facilitates pathogen tissue penetration and produces interstitial brain edema. Glia 60, 137-146. doi: 10.1002/glia.21256

Ide, M., Harris, M., Stevens, A., Sussams, R., Hopkins, V., Culliford, D., et al. (2016). Periodontitis and cognitive decline in Alzheimers disease. PLoS One 11:e0151081. doi: 10.1371/journal.pone.0151081

Iovino, F., Engelen-Lee, J. Y., Brouwer, M., van de Beek, D., van der Ende, A., Valls Seron, M., et al. (2017). pIgR and PECAM-1 bind to pneumococcal adhesins RrgA and PspC mediating bacterial brain invasion. J. Exp. Med. 214, 1619-1630. doi: 10.1084/jem.20161668

Iovino, F., Nannapaneni, P., Henriques-Normark, B., and Normark, S. (2020). The impact of the ancillary pilus-1 protein RrgA of Streptococcus pneumoniae on colonization and disease. Mol. Microbiol. 113, 650-658. doi: 10.1111/mmi. 14451

Iovino, F., Thorsdottir, S., and Henriques-Normark, B. (2018). Receptor blockade: a novel approach to protect the brain from pneumococcal invasion. J. Infect. Dis. 218, 476-484. doi: 10.1093/infdis/jiy193

Iovino, F., Seinen, J., Henriques-Normark, B., and Maarten Van Dijl, J. (2016). How does streptococcus pneumoniae invade the brain? Trends Microbiol. 24, 307-315. doi: 10.1016/j.tim.2015.12.012

Jaruvongvanich, V., Sanguankeo, A., Jaruvongvanich, S., and Upala, S. (2016). Association between Helicobacter pylori infection and multiple sclerosis: a systematic review and meta-analysis. Mult. Scler. Relat. Disord. 7, 92-97. doi: 10.1016/j.msard.2016.03.013

Kalin, M., Kanclerski, K., Granström, M., and Möllby, R. (1987). Diagnosis of pneumococcal pneumonia by enzyme-linked immunosorbent assay of antibodies to Pneumococcal hemolysin (pneumolysin). J. Clin. Microbiol. 25, 226-229. doi: 10.1128/JCM.25.2.226-229.1987

Kamei, S. (2016). Cognitive impairment in patients with bacterial meningitis and encephalitides. Brain Nerve 68, 317-327. doi: 10.11477/mf.1416200400

Kany, S., Tilmann Vollrath, J., and Relja, B. (2019). Cytokines in Inflammatory disease. Int. J. Mol. Sci. 20:6008. doi: 10.3390/ijms20236008

Katan, M., Moon, Y. P., Paik, M. C., Sacco, R. L., Wright, C. B., Elkind, M. S., et al. (2013). Infectious burden and cognitive function: the Northern Manhattan study. Neurology 80, 1209-1215. doi: 10.1212/WNL.0b013e3182896e79 
Kawasaki, T., and Kawai, T. (2014). Toll-Like Receptor Signaling Pathways. Front. Immunol. 5:461. doi: 10.1128/microbiolspec.MCHD-0040-2016

Kielian, T. (2009). Overview of Toll-Like Receptors in the CNS. New York, NY: Springer Berlin Heidelberg.

Kietzman, C., and Tuomanen, E. (2019). Acute bacterial meningitis: challenges to better antibiotic therapy. ACS Infect. Dis. 5, 1987-1995. doi: $10.1021 /$ acsinfecdis.9b00122

Kim, K. S. (2003). Pathogenesis of bacterial meningitis: from bacteraemia to neuronal injury. Nat. Rev. Neurosci. 4, 376-385. doi: 10.1038/nrn1103

Kim, K. S. (2008). Mechanisms of microbial traversal of the blood-brain barrier. Nat. Rev. Microbiol. 6, 625-634. doi: 10.1038/nrmicro1952

Kobayashi, Y., Kuhara, T., Oki, M., and Xiao, J. Z. (2019). Effects of Bifidobacterium breve Al on the cognitive function of older adults with memory complaints: a randomised, double-blind, placebo-controlled trial. Benef. Microbes 10, 511-520. doi: 10.3920/BM2018.0170

Kopitar-Jerala, N. (2015). Innate immune response in brain, NF-к b signaling and cystatins. Front. Mol. Neurosci. 8:73. doi: 10.3389/fnmol.2015. 00073

Kountouras, J., Boziki, M., Gavalas, E., Zavos, C., Grigoriadis, N., Deretzi, G., et al. (2009). Eradication of Helicobacter pylori may be beneficial in the management of Alzheimers disease. J. Neurol. 256, 758-767. doi: 10.1007/s00415-009 $-5011-z$

Kountouras, J., Tsolaki, M., Gavalas, E., Boziki, M., Zavos, C., Karatzoglou, P., et al. (2006). Relationship between Helicobacter pylori infection and Alzheimer disease. Neurology 66, 938-940. doi: 10.1212/01.wnl.0000203644. $68059.5 f$

Leib, S. L. (2001). Inhibition of matrix metalloproteinases and tumour necrosis factor alpha converting enzyme as adjuvant therapy in pneumococcal meningitis. Brain 124, 1734-1742. doi: 10.1093/brain/124. 9.1734

Leib, S. L., and Täuber, M. G. (1999). Pathogenesis of bacterial meningitis. Infect. Dis. Clin. North Am. 13, 527-548. doi: 10.1016/s0891-5520(05)70093-3

Li, Y., Yin, L., Fan, Z., Su, B., Chen, Y., Ma, Y., et al. (2020). Microglia: a potential therapeutic target for sepsis-associated encephalopathy and sepsisassociated chronic pain. Front. Pharmacol. 583:11. doi: 10.3389/fphar.2020. 600421

Liechti, F. D., Grandgirard, D., and Leib, S. L. (2015). Bacterial meningitis: insights into pathogenesis and evaluation of new treatment options: a perspective from experimental studies. Future Microbiol. 10, 1195-1213. doi: 10.2217/fmb.15.43

Liu, X., Chauhan, V. S., Young, A. B., and Marriott, I. (2010). NOD2 mediates inflammatory responses of primary murine glia to Streptococcus pneumoniae. Glia 58, 839-847. doi: 10.1002/glia.20968

Lorenz, E., Chemotti, D. C., Jiang, A. L., and McDougal, L. D. (2005). Differential involvement of toll-like receptors 2 and 4 in the host response to acute respiratory infections with wild-type and mutant haemophilus influenzae strains. Infect. Immun. 73, 2075-2082. doi: 10.1128/IAI.73.4.2075-20 82.2005

Lucas, M. J., Brouwer, L. D., and Van De Beek, D. (2016). Neurological sequelae of bacterial meningitis. J. Infect. 73, 18-27. doi: 10.1016/j.jinf.2016.04.009

Lyman, M., Lloyd, D. G., Ji, X., Vizcaychipi, M. P., and Ma, D. (2014). Neuroinflammation: the role and consequences. Neurosci. Res. 79, 1-12. doi: 10.1016/j.neures.2013.10.004

Maldiney, T., Bonnot, D., Anzala, N., Albac, S., Labrousse, D., Varon, E., et al. (2021). In vitro antimicrobial activity of daptomycin alone and in adjunction to either amoxicillin, cefotaxime or rifampin against the main pathogens responsible for bacterial meningitis in adults. J. Global Antimicrob. Resist. 25, 193-198. doi: 10.1016/j.jgar.2021.03.007

Malley, R., Henneke, P., Morse, S. C., Cieslewicz, S. C., Lipsitch, M., Thompson, C. M., et al. (2003). Recognition of pneumolysin by Toll- like receptor 4 confers resistance to pneumococcal infection. Proc. Natl. Acad. Sci. U S A 100, 1966-1971. doi: 10.1073/pnas.0435928100

Massari, P., Visintin, A., Gunawardana, J., Halmen, K. A., King, C. A., Golenbock, D. T., et al. (2006). Meningococcal Porin PorB binds to TLR2 and 6 requires TLR1 for signaling. J. Immunol. 176, 2373-2380. doi: $10.4049 /$ jimmunol.176.4.2373

McIntyre, P. B., OBrien, K. L., Greenwood, B., and Van De Beek, D. (2012). Effect of vaccines on bacterial meningitis worldwide. The Lancet 380, 1703-1711. doi: $10.1016 / S 0140-6736(12) 61187-8$
McKay, K. A., Kwan, V., Duggan, T., and Tremlett, H. (2015). Risk factors associated with the onset of relapsing-remitting and primary progressive multiple sclerosis: a systematic review. BioMed Res. Int. 2015, 817238-817238. doi: $10.1155 / 2015 / 817238$

McManus, R. M., and Heneka, M. T. (2017). Role of neuroinflammation in neurodegeneration: new insights. Alzheimers Res. Ther. 9:14. doi: 10.1186/s13195-017-0241-2

McNeela, E. A., Burke, Á., Neill, D. R., Baxter, C., Fernandes, V. E., Ferreira, D., et al. (2010). Pneumolysin activates the nlrp3 inflammasome and promotes proinflammatory cytokines independently of TLR4. PLoS Pathogens 6:e1001191. doi: 10.1371/journal.ppat.1001191

Meneses, G., Cárdenas, G., Espinosa, A., Rassy, D., Pérez-Osorio, I. N., Bárcena, B., et al. (2019). Sepsis: developing new alternatives to reduce neuroinflammation and attenuate brain injury. Ann. N Y Acad. Sci. 1437, 43-56. doi: 10.1111/nyas. 13985

Miklossy, J. (2011). Emerging roles of pathogens in Alzheimer disease. Expert Rev. Mol. Med. 13:e30. doi: 10.1017/S1462399411002006

Mitchell, A. J., Yau, B., McQuillan, J. A., Ball, H. J., Khoon Too, L., Abtin, A., et al. (2012). Inflammasome-dependent IFN- $\gamma$ drives pathogenesis 6 in Streptococcus Pneumoniae Meningitis. J. Immunol. 189, 4970-4980. doi: 10.4049/jimmunol. 1201687

Mitchell, T. J., and Dalziel, C. E. (2014). The Biology of Pneumolysin. Netherlands: Springer.

Mogensen, T. H. (2006). Live Streptococcus pneumoniae, Haemophilus influenzae and Neisseria meningitidis activate the inflammatory response through Toll-like receptors 2, 4 and 9 in 6 species-specific patterns. J. Leukocyte Biol. 80, 267-277. doi: 10.1189/jlb.1105626

Mohammed, B. J., Mitchell, T. J., Andrew, P. W., Hirst, R. A., and O'Callaghan, C. (1999). The effect of the pneumococcal toxin, pneumolysin on brain ependymal cilia. Microb. Pathog. 27, 303-309. doi: 10.1006/mpat.1999.0306

Mook-Kanamori, B. B., Geldhoff, M., Van Der Poll, T., and Van De Beek, D. (2011). Pathogenesis and pathophysiology of Pneumococcal Meningitis. Clin. Microbiol. Rev. 24, 557-591. doi: 10.1128/CMR.00008-11

Müller, A., Günther, D., Düx, F., Naumann, M., Meyer, T. F., Rudel, T., et al. (1999). Neisserial porin (PorB) causes rapid calcium influx in target cells and induces apoptosis by the activation of cysteine proteases. EMBO J. 18, 339-352. doi: 10.1093/emboj/18.2.339

Mustafa, M. M., Lebel, M. H., Ramilo, O., Olsen, K. D., Reisch, J. S., Beutler, B., et al. (1989). Correlation of interleukin-1 $\beta$ and cachectin concentrations in cerebrospinal fluid and outcome from bacterial meningitis. J. Pediatr. 115, 208-213. doi: 10.1016/s0022-3476(89)80067-8

Naito, M., Johkura, K., Momoo, T., Nomiya, T., Kudo, Y., and Kuroiwa, Y. (2010). Dementia and capsular genu ischemia in patients with severe bacterial meningitis. Neurol. Sci. 31, 133-136. doi: 10.1007/s10072-009-0168-x

Natalwala, A., Potluri, R., Uppal, H., and Heun, R. (2008). Reasons for hospital admissions in dementia patients in Birmingham, UK, during 2002-2007. Dement. Geriatr. Cogn. Disord. 26, 499-505. doi: 10.1159/000171044

Olstad, E. W., Ringers, C., Hansen, J. N., Wens, A., Brandt, C., Wachten, D., et al. (2019). Ciliary beating compartmentalizes 6 cerebrospinal fluid flow in the brain and regulates ventricular development. Curr. Biol. 29, 229-241.e6. doi: 10.1016/j.cub.2018.11.059

Paley, E. L. (2019). Discovery of gut bacteria specific to Alzheimers associated diseases is a clue to understanding disease etiology: meta-analysis of population-based data on human gut metagenomics and metabolomics. J. Alzheimers Dis. 72, 319-355. doi: 10.3233/JAD-190873

Patrick, K. L., Bell, S. L., Weindel, C. G., and Watson, R. O. (2019). Exploring the "multiple-hit hypothesis" of neurodegenerative disease: bacterial infection comes up to bat. Front. Cell. Infect. Microbiol. 9:138. doi: 10.3389/fcimb.2019. 00138

Principi, N., and Esposito, S. (2020). Bacterial meningitis: new treatment options to reduce the risk of brain damage. Exp. Opin. Pharmacother. 21, 97-105. doi: 10.1080/14656566.2019.1685497

Rai, P., Ian Jun Jie Tay, M.-P., Li, N., Ackerman, S., He, F., Kwang, J., et al. (2015). Streptococcus pneumoniae secretes hydrogen peroxide leading to DNA damage and apoptosis in lung cells. Proc. Natl. Acad. Sci. U S A 112, E3421-E3430. doi: 10.1073/pnas.1424144112

Reiß, A., Braun, J. S., Jäger, K., Freyer, D., Laube, G., Bührer, C., et al. (2011). Bacterial pore-forming cytolysins induce neuronal damage in a rat 
model of neonatal meningitis. J. Infect. Dis. 203, 393-400. doi: 10.1089/jayao. 2020.0228

Rengel, K. F., Hayhurst, C., Pandharipande, P. P., and Hughes, C. G. (2019). Longterm cognitive and functional impairments after critical illness. Anesth. Analg. 128, 772-780. doi: 10.1213/ANE.0000000000004066

Robert, A. H., Gosai, B., Rutman, A., Christopher, J. C., Nicotera, P., Peter, W. A., et al. (2008). Streptococcus pneumoniae deficient in pneumolysin or autolysin has reduced virulence in meningitis. J. Infect. Dis. 197, 744-751. doi: 10.1128/JB.06231-11

Rosado, J. A., and Sage, S. O. (2000). The actin cytoskeleton in store-mediated calcium entry. J. Physiol. 526, 221-229. doi: 10.1111/j.1469-7793.2000.t01-200221.x

Royer, P.-J., Rogers, A. J., Wooldridge, K. G., Tighe, P., Mahdavi, J., Rittig, M. G., et al. (2013). Deciphering the contribution of human meningothelial cells to the inflammatory and antimicrobial response at the meninges. Infect. Immun. 81, 4299-4310. doi: 10.1128/IAI.00477-13

Saint-Pol, J., Gosselet, F., Duban-Deweer, S., Pottiez, G., and Karamanos, Y. (2020). Targeting and crossing the blood-brain barrier with extracellular vesicles. Cells 9, 686-851. doi: 10.3390/cells9040851

Schmeck, B., Huber, S., Moog, K., Zahlten, J., Hocke, A. C., Opitz, B., et al. (2006). Pneumococci induced TLR- and Rac1-dependent NF-кB- 690 recruitment to the IL-8 promoter in lung epithelial cells. Am. J. Physiol. Lung Cell. Mol. Physiol. 290, L730-L737. doi: 10.1152/ajplung.00271.2005

Schmidt, H., Heimann, B., Djukic, M., Mazurek, C., Fels, C., Wallesch, C. W., et al. (2006). Neuropsychological sequelae of bacterial and viral meningitis. Brain 129, 333-345. doi: 10.1093/brain/awh711

Schröder, N. W. J., Morath, S., Alexander, C., Hamann, L., Hartung, T., Zähringer, U., et al. (2003). Lipoteichoic acid (LTA) of streptococcus pneumoniaeand staphylococcus aureus activates immune cells via toll-like receptor (TLR)-2, lipopolysaccharide-binding protein (LBP) and CD14, whereas TLR-4 and MD-2 Are Not Involved. J. Biol. Chem. 278, 15587-15594. doi: $10.1002 /$ alz.12323

Shahjin, F., Chand, S., and Yelamanchili, S. V. (2020). Extracellular vesicles as drug delivery vehicles to the central nervous system. J. Neurol. Pharmacol. 15, 443-458. doi: 10.1007/s11481-019-09875-w

Sharief, M. K., Ciardi, M., and Thompson, E. J. (1992). Blood-brain barrier damage in patients with bacterial meningitis: association with tumor necrosis factor- $\alpha$ but not interleukin-I $\beta$. J. Infect. Dis. 166, 350-358. doi: 10.1093/infdis/ 166.2.350

Shen, X., Yang, H., Wu, Y., Zhang, D., and Jiang, H. (2017). Metaanalysis: association of Helicobacter pylori infection with Parkinsons diseases. Helicobacter 22:851. doi: 10.3390/cells9040851

Singhi, P., Bansal, A., Geeta, P., and Singhi, S. (2007). Predictors of long term neurological outcome in bacterial meningitis. Indian J. Pediatr. 74, 369-374. doi: 10.1007/s12098-007-0062-6

Sochocka, M., Zwolińska, K., and Leszek, J. (2017). The infectious etiology of Alzheimers disease. Curr. Neuropharmacol. 15, 996-1009. doi: 10.2174/1570159X15666170313122937

Sorbara, M. T., and Philpott, D. J. (2011). Peptidoglycan: a critical activator of the mammalian immune system during infection and homeostasis. Immunol. Rev. 243, 40-60. doi: 10.1111/j.1600-065X.2011.01047.x

Sørensen, H., Mortensen, E., Reinisch, J., and Mednick, S. (2008). Association between prenatal exposure to bacterial infection and risk of schizophrenia. Schizophr. Bull. 35, 631-637. doi: 10.1093/schbul/sbn121

Spellerberg, B., Cundell, D. R., Sandros, J., Pearce, B. J., Idänpään-Heikkilä, I., Rosenow, C., et al. (1996). Pyruvate oxidase, as a determinant of virulence in Streptococcus pneumoniae. Mol. Microbiol. 19, 803-813. doi: 10.1046/j.13652958.1996.425954.x

Stolp, H. B., and Dziegielewska, K. M. (2009). Review: role of developmental inflammation and blood-brain barrier dysfunction in neurodevelopmental and neurodegenerative diseases. Neuropathol. App. Neurobiol. 35, 132-146. doi: 10.1111/j.1365-2990.2008.01005.x

Strandberg, T. E., Pitkala, K. H., Linnavuori, K., and Tilvis, R. S. (2004). Cognitive impairment and infectious burden in the elderly. Arch. Gerontol. Geriatr. Suppl. 9, 419-423. doi: 10.1016/j.archger.2004.04.053

Stringaris, A. K., Geisenhainer, J., Bergmann, F., Balshüsemann, C., Lee, U., Zysk, G., et al. (2002). Neurotoxicity of pneumolysin, a major pneumococcal virulence factor, involves calcium influx and depends on activation of p38 mitogen-activated protein kinase. Neurobiol. Dis. 11, 355-368. doi: $10.1006 /$ nbdi.2002.0561

Su, T. W., Wu, L. L., and Lin, C. P. (2012). The prevalence of dementia and depression in Taiwanese institutionalized leprosy patients and the effectiveness evaluation of reminiscence therapy - a longitudinal, single-blind, randomized control study. Int. J. Geriatr. Psychiatry 27, 187-196. doi: 10.1002/gps.2707

Swartz, M. N. (2004). Bacterial meningitis-a view of the past 90 years. N. Engl. J. Med. 351, 1826-1828. doi: 10.1056/NEJMp048246

Tabusi, M., Thorsdottir, S., Lysandrou, M., Narciso, A. R., Minoia, M., Srambickal, C. V., et al. (2021). Neuronal death in pneumococcal meningitis is triggered by pneumolysin and RrgA interactions with $\beta$-actin. PLoS Pathog. 17:e1009432. doi: 10.1371/journal.ppat.1009432

Takeda, K., Kaisho, T., and Akira, S. (2003). Toll-like receptors. Annu. Rev. Immunol. 21, 335-376. doi: 10.1002/0471142735.im1412s109

Thigpen, M. C., Whitney, C. G., Messonnier, N. E., Zell, E. R., Lynfield, R., Hadler, J. L., et al. (2011). Bacterial meningitis in the United States, 1998-2007. N. Engl. J. Med. 364, 2016-2025. doi: 10.1056/NEJMoa1005384

Thorsdottir, S., Henriques-Normark, B., and Iovino, F. (2019). The role of microglia in bacterial meningitis: inflammatory response, experimental models and new neuroprotective therapeutic strategies. Front. Microbiol. 10:576. doi: $10.3389 /$ fmicb. 2019.00576

Too, L. K., Hunt, N., and Simunovic, M. P. (2021). The role of inflammation and infection in age-related neurodegenerative diseases: lessons from bacterial meningitis applied to Alzheimer disease and age-related macular degeneration. Front. Cell. Neurosci. 15:635486. doi: 10.3389/fncel.2021.635486

Tran, T. T. T., Corsini, S., Kellingray, L., Hegarty, C., Le Gall, G., Narbad, A., et al. (2019). APOE genotype influences the gut microbiome structure and function in humans and mice: relevance for Alzheimers disease pathophysiology. FASEB J. 33, 8221-8231. doi: 10.1096/fj.201900071R

Tzeng, Y.-L., and Stephens, D. S. (2000). Epidemiology and pathogenesis of Neisseria meningitidis. Microbes Infect. 2, 687-700. doi: 10.1016/s12864579(00)00356-7

Van De Beek, D., Schmand, B., De Gans, J., Weisfelt, M., Vaessen, H., Dankert, J., et al (2002). Cognitive impairment in adults with good recovery after bacterial meningitis. J. Infect. Dis. 186, 1047-1052. doi: 10.1086/344229

Van De Beek, D., Brouwer, M., Hasbun, R., Koedel, U., Whitney, C. G., and Wijdicks, E. (2016). Community-acquired bacterial meningitis. Nat. Rev. Disease Primers 2:16074. doi: 10.1038/nrdp.2016.74

Waage, A., Halstensen, A., Shalaby, R., Brandtzaeg, P., Kierulf, P., and Espevik, T. (1989). Local production of tumor necrosis factor alpha, interleukin 1 and interleukin 6 in meningococcal meningitis. Relation to the inflammatory response. J. Exp. Med. 170, 1859-1867. doi: 10.1084/jem.170. 6.1859

Wahl, B., OBrien, K. L., Greenbaum, A., Majumder, A., Liu, L., Chu, Y., et al. (2018). Burden of Streptococcus pneumoniae and Haemophilus influenzae type b disease in children in the era of conjugate vaccines: global, regional and national estimates for 2000-2015. The Lancet Global Health 6, e744-e757. doi: 10.1016/S2214-109X(18)30247-X

Wall, E. C., Gordon, S. B., Hussain, S., Goonetilleke, U. R. S., Gritzfeld, J., Scarborough, M., et al. (2012). Persistence of pneumolysin in the cerebrospinal fluid of patients with pneumococcal meningitis is associated with mortality. Clin. Infect. Dis. 54, 701-705. doi: 10.1093/cid/cir926

Walsh, J. G., Muruve, D. A., and Power, C. (2014). Inflammasomes in the CNS. Nat. Rev. Neurosci. 15, 84-97. doi: 10.1038/nrn3638

Wang, X., Moser, C., Louboutin, J.-P., Lysenko, E. S., Weiner, D. J., Weiser, J. N., et al. (2002). Toll-like receptor 4 mediates innate immune responses to haemophilus influenzae infection in mouse lung. J. Immunol. 168, 810-815. doi: 10.4049/jimmunol.168.2.810

Weisfelt, M., Van De Beek, D., Hoogman, M., Hardeman, C., De Gans, J., Schmand, B., et al. (2006). Cognitive outcome in adults with moderate disability after pneumococcal meningitis. J. Infect. 52, 433-439. doi: 10.1016/j.jinf.2005. 08.014

Wellmer, A., Zysk, G., Gerber, J., Kunst, T., Von Mering, M., Bunkowski, S., et al. (2002). Decreased virulence of a pneumolysin- deficient strain of streptococcus pneumoniae in murine meningitis. Infect. Immun. 70, 6504-6508. doi: 10.1128/iai.70.11.6504-6508.2002

Winter, A. J., Comis, S. D., Osborne, M. P., Tarlow, M. J., Stephen, J., Andrew, P. W., et al. (1997). A role for pneumolysin but not neuraminidase in 
the hearing loss and cochlear damage induced by experimental pneumococcal meningitis in guinea pigs. Infect. Immun. 65, 4411-4418. doi: 10.1128/IAI.65. 11.4411-4418.1997

Woodhams, K. L., Chan, J. M., Lenz, J. D., Hackett, K. T., and Dillard, J. P. (2013). Peptidoglycan fragment release from Neisseria meningitidis. Infect. Immun. 81, 3490-3498. doi: 10.1128/IAI.00279-13

Yao, G., Wang, P., Luo, X. D., Yu, T. M., Harris, R. A., and Zhang, X. M. (2016). Meta-analysis of association between Helicobacter pylori infection and multiple sclerosis. Neurosci. Lett. 620, 1-7. doi: 10.1016/j.neulet.2016.03.037

Zhang, Z., Guan, J., Jiang, Z., Yang, Y., Liu, J., Hua, W., et al. (2019). Brain-targeted drug delivery by manipulating protein corona functions. Nat. Commun. 10:3561. doi: 10.1038/s41467-019-11593-Z

Zhou, Y., Peng, Z., Seven, E. S., and Leblanc, R. M. (2018). Crossing the bloodbrain barrier with nanoparticles. J. Control. Rel. 270, 290-303. doi: 10.1016/j. jconrel.2017.12.015
Zughaier, S. M. (2011). Neisseria meningitidis capsular polysaccharides induce inflammatory responses via TLR2 and TLR4-MD-2. J. Leukoc. Biol. 89, 469-480. doi: 10.1189/jlb.0610369

Conflict of Interest: The authors declare that the research was conducted in the absence of any commercial or financial relationships that could be construed as a potential conflict of interest.

Copyright $\odot 2021$ Farmen, Tofiñ-Vian and Iovino. This is an open-access article distributed under the terms of the Creative Commons Attribution License (CC BY). The use, distribution or reproduction in other forums is permitted, provided the original author(s) and the copyright owner(s) are credited and that the original publication in this journal is cited, in accordance with accepted academic practice. No use, distribution or reproduction is permitted which does not comply with these terms. 